\title{
Kokulu Ardıç'ın (Juniperus foetidissima Willd.) Türkiye'de Günümüz ve Gelecekteki Potansiyel Yayılışının Makine Öğrenmesi ile Modellenmesi
}

\author{
E. Seda Arslan ${ }^{1}$, Derya Gülçin² ${ }^{2}$ Ayşe Gül Sarıkaya ${ }^{3}$, Zafer Ölmez ${ }^{4}$, Süleyman Gülcü ${ }^{5}$, İsmail Şen ${ }^{6}$, Ömer K. \\ Örücü ${ }^{1}$ \\ ${ }^{1}$ Süleyman Demirel Üniversitesi Mimarlık Fakültesi Peyzaj Mimarlığı Bölümü, Isparta (ORCID: 0000-0003-1592-5180, ORCID: 0000-0002-2162-7553) \\ ${ }^{2}$ Aydın Adnan Menderes Üniversitesi Ziraat Fakültesi Peyzaj Mimarlı̆̆ı Bölümü, Aydın (ORCID: 0000-0001-7118-0174) \\ ${ }^{3}$ Bursa Teknik Üniversitesi Orman Fakültesi Orman Mühendisliği Bölümü, Bursa (ORCID: 0000-0002-0641-4445) \\ ${ }^{4}$ Artvin Çoruh Üniversitesi Orman Fakültesi Orman Mühendisliği Bölümü, Artvin (ORCID: 0000-0001-6199-6284) \\ 5 Isparta Uygulamalı Bilimler Üniversitesi Orman Fakültesi Orman Mühendisliği Bölümü, Isparta (ORCID: 0000-0002-1995-8580) \\ ${ }^{6}$ Isparta Uygulamalı Bilimler Üniversitesi Teknoloji Fakültesi Biyomedikal Mühendisliği Bölümü, Isparta (ORCID: 0000-0002-9905-3537)
}

(Illk Geliş Tarihi Aralık 2020 ve Kabul Tarihi Ocak 2021)

(DOI: 10.31590/ejosat.848961)

ATIF/REFERENCE: Arslan, E. S., Gülçin, D., Sarıkaya, A. G., Ölmez, Z., Gülcü, S., Şen, İ., \& Örücü, Ö. K. (2021). Kokulu Ardıç'ın (Juniperus foetidissiman Willd.) Türkiye'de Günümüz ve Gelecekteki Potansiyel Yayılıı̧ının Makine Öğrenmesi ile Modellenmesi. Avrupa Bilim ve Teknoloji Dergisi, (22), 1-12.

$\ddot{O} \mathbf{z}$

Küresel ölçekte incelendiğinde, biyolojik çeşitlilik sağlama ve karbon tutma bakımından önemli ekosistemler arasındaki ormanların, biyotik, abiyotik ve antropojenik etkenler nedeniyle önemli değişimler içerisinde olduğu görülmektedir. Bu süreçte, iklimin belirleyici bir rolü olduğu kabul edilmiştir. Buna ek olarak, değişen iklim koşullarının, ormanların dağılımını, bileşimini, işlevini önemli oranda değiş̧tireceği ve sonuç olarak biyolojik çeşitliliği tehdit edeceği öngörülmüştür. Bu çalışmanın amac1; Türkiye'de doğal yayılış gösteren ve orman ekosistemine ekolojik katkısı ile ön planda olan türler arasındaki kokulu ardıçın (Juniperus foetidissima Willd.), günümüz ve gelecekteki potansiyel coğrafi dağılımının tür varlığı verisi ve çevresel değişkenler (biyoiklimsel değişkenler ve yükseklik) ile modellenmesidir. Ayrıca, J. foetidissima Willd.'nin potansiyel yayılış alanlarının, günümüzde ve gelecekte alansal ve konumsal olarak nasıl değişiklik gösterdiği de değişim analizleri ile ortaya konmuştur. Bu kapsamda, tür dağılımı SSP2 4.5 ve SSP5 8.5 senaryolarına göre 2041-2060 ve 2081-2100 zaman aralıklarını kapsayacak şekilde belirlenmiştir. Maksimum entropi modelinin kullanıldığı bu çalışmada, her bir tahmin değişkeninin göreceli katkısı Jackknife (çek-çıkar) testi ile belirlenmiş, çoklu doğrusallığı önlemek amacıyla Pearson korelasyonundan yararlanılmışıır. Bulgular, J. foetidissima'nın yayılışında en önemli değişkenlerin sırasıyla yükseklik, soğuk ayın en az sıcaklığı (BIO6) ve en nemli mevsimin ortalama sıcaklığı (BIO8) olduğunu göstermiş̧tir. Tahmin doğruluğunu ifade eden ROC eğrisi, kullanılan modelin simülasyon gücünün çok yüksek olduğunu ifade etmektedir. Model sonuçlarına göre, J. foetidissima'nın potansiyel yayılışında önemli miktarda değişiklikler olacağ ve türün iklim değişikliğinden ciddi oranda olumsuz etkileneceği tahmin edilmiştir. Değişim analizi sonuçları, habitat uygunluğundaki alansal kaybın, kazanç miktarından daha fazla olduğunu göstermektedir. Sonuç olarak, bu çalışmada $J$. foetidissima'nın iklim değişikliklerine adaptasyon direncinin düşük olacağı ve dolayısıyla tür koruma çalışmalarına dâhil edilmesi gerektiği vurgulanmıştır. Bu çalışmanın bulguları, türün gelecekte sürdürülebilmesi ve korunmasına yönelik güçlü stratejilerin belirlenebilmesi amacıyla kullanılabilir.

Anahtar Kelimeler: Kokulu ardıç, tür dağılım modeli, değişim analizi, MaxEnt

\section{Modeling of the current and future potential distribution of Stinking juniper (Juniperus foetidissima Willd.) in Turkey with machine learning techniques}

\begin{abstract}
Forest ecosystems, which are seen relevant in terms of providing biodiversity and capturing carbon, have been affected by significant changes due to biotic, abiotic, and anthropogenic factors over time. There is no doubt that climate has a decisive role in this process. In addition, previous studies claim that changing climatic conditions will significantly alter the distribution, composition, and function of forests and, consequently, threaten biodiversity. This study aims to model the present and future potential geographic distribution of the stinking juniper (Juniperus foetidissima Willd.), which has a natural and potential distribution in Turkey as an ecologically important species, with presence data and diverse environmental variables (bioclimatic predictors and altitude). In this context, species distributions were modelled to cover the 2041-2060 and 2081-2100 periods under the SSP2 4.5 and SSP5 8.5 scenarios. Using
\end{abstract}


maximum entropy model, this study analyzed the relative contribution of each environmental predictor by Jackknife test. In order prevent high correlation and multicollinearity, the correlated factors were determined by Pearson correlation coefficient. The findings showed that the most significant variables in the distribution of $J$. foetidissima were elevation, minimum temperature of coldest month (BIO6), and mean temperature of wettest quarter (BIO8), respectively. Representing the prediction accuracy, ROC curve indicates that the predictive power of the model used in this study was great. According to the model results, it was predicted that there would be significant changes in the potential distribution of $J$. foetidissima and this species would be seriously adversely affected by climate change. The results of change analysis pointed out that the spatial loss in habitat suitability was greater than the amount of gain. As a result, this study suggested that $J$. foetidissima's adaptation resistance to climate changes would be low, and therefore should be incorporated into species conservation. The findings of this study can be used to identify robust strategies for the future survival and conservation of the species.

Keywords: Stinking juniper, species distribution model, change analysis, MaxEnt

\section{Giriş}

İklim değişikliği; biyolojik çeşitliliği ve türlerin coğrafi dağılımını olumsuz yönde etkileyerek bitki türlerinin yok olma tehlikesini artırmaktadır (Chakraborty vd., 2016; Zhao vd., 2020). İklim değişikliği nedeniyle, bitkilerin yüksek rakımlara göç ettiği ve önümüzdeki 100 yıl içerisinde de bu durumun artarak devam edeceği küresel çaptaki bilimsel çalışma ve gözlemlerle tespit edilmiştir (Abdelaal vd., 2019; Arslan vd., 2020; Li vd., 2020). Hükümetler arası İklim Değişikliği Paneli (IPCC) tarafından sunulan raporlara göre, küresel ölçekte sıcaklıklar her geçen yıl artmaktadır (IPCC, 2014). 21. yüzyılın sonunda, küresel sıcaklıkların mevcut sıcaklıklara göre en az 0,3-1,7 ${ }^{\circ} \mathrm{C}$ ile en çok $2,6-4,8{ }^{\circ} \mathrm{C}$ daha yüksek olacağı tahmin edilmektedir (Stocker vd., 2014). Sıcaklık artışına paralel olarak, atmosferik karbondioksit $\left(\mathrm{CO}_{2}\right)$ seviyesi ve diğer sera gazlarının artacağı öngörülmekte ve bu durumun önemli miktarda bireysel tür kaybına yol açması beklenmektedir (Friend vd., 2014). Dolayısıyla, iklim değişikliği çerçevesinde biyolojik çeşitliliği koruma stratejilerinin belirlenebilmesi için ekolojik açıdan değerli türlerin coğrafi dağılımındaki potansiyel değişikliklerin detaylı olarak analiz edilmesi gereklidir (Manish vd., 2016; Naudiyal vd., 2021; Ncube vd., 2020; Prevéy vd., 2020).

İklim değişikliğine türlerin verdiği biyolojik tepkiler üç farklı durum ile sonuçlanabilir (Chakraborty vd., 2016; Dyderski vd., 2018). Birincisi; hedef tür, ekolojik nişleri takip ederek başka bir bölgeye göç edebilir (Abdelaal vd., 2019; Zhang vd., 2018). İkincisi; tür, mevcut konumda farklı iklimsel koşullara uyum sağlayabilir (Du vd., 2021; Rana vd., 2020; Yi vd., 2016). Üçüncüsü ise; türde, yerel yok oluş gözlemlenebilir (Wiens, 2016). İklim değişikliği özellikle iklim koşullarına uyum sağlayamayan ve bu nedenle nesli tükenme tehlikesi ile karşılaşan endemik türleri etkilemektedir (Damschen vd., 2010; Silva vd., 2019). Pek çok endemik takson, dar coğrafi dağılım ve sınırlı habitat yayılışları ile küresel yok olma tehlikesiyle karşı karşıya olduğu için tehdit altındaki türleri ifade eden IUCN kırmızı listesine dâhil edilmiştir (Kaky ve Gilbert, 2019; Le Breton vd., 2019). Bu türlerin korunması, habitat uygunluklarını göz önünde bulundurarak, günümüz ve gelecekteki koşullar altında tür varlığını ve kalıcılığını sağlayan çevresel faktörlerin belirlenmesi ile mümkündür (Mod vd., 2016; Wilson vd., 2020). $\mathrm{Bu}$ türleri korumak amacıyla atılacak ilk adım, mevcut coğrafi dağılımı, habitat uygunluğunu ve yok olma riskine maruz bırakan tehditleri belirlemektir (Akyol ve Örücü, 2019; Wan vd., 2017).

Ekolojik niş, bir türün hayatta kalabilmesi ve varlığını devam ettirebilmesi için popülasyon içerisindeki üreme yeteneğini sürdürdüğü alan ve koşulların etkileşimini ifade etmektedir (Choudhary vd., 2019). Ekolojik nişler; türlerin kökeni, kalıcılığı, dağılımı ve rekabet kapasitesinin açıklanmasında aktif rol oynarlar (Chase ve Leibold, 2003; Peterson vd., 2011). İklim, toprak özellikleri, topografya, arazi kullanımı ve biyolojik etkileşimler, türlerin çeşitli coğrafi dağılımı ve ekolojik niş potansiyelinin belirlenmesinde temel faktörler olarak kabul edilmektedir (Regos vd., 2019; Scherrer ve Guisan, 2019).

Tür dağılımının modellenmesi; koruma, ekoloji, biyocoğrafya, evrim, istilacı tür kontrolü ve yaban hayatı yönetimi çalışmalarında önemli bir araç haline gelmiştir (Barve vd., 2011; Elith vd., 2006; Kariyawasam vd., 2019; Miller, 2010). Maksimum entropi (MaxEnt), türlerin uygun coğrafi dağılımını modellemek için kullanılan ve tür dağılım modelini temel alan bir algoritmadır (Elith vd., 2011). MaxEnt diğer modellere (BIOCLIM, DOMAIN, GARP, vb.) göre eksik veri kümeleriyle bile oldukça iyi performans göstermektedir (Feng vd., 2019; Peterson vd., 2007). Buna ek olarak, MaxEnt; kısa model çalışma süresi, kolay model uygulaması, küçük örnek boyutu gereksinimleri ve yüksek simülasyon hassasiyeti gibi birçok avantaja sahiptir (Li vd., 2020; Pearson vd., 2007; Phillips vd., 2006).

Kokulu ardıç (Juniperus foetidissima Willd.), Türkiye florasında doğal yayılışı olan sosyo-ekonomik ve ekolojik katkıları olan bir türdür. Zaman içerisinde meydana gelen doğal rejenarasyon, ağaç kesme ve orman alanlarında yasak otlatma sonucunda, aralarında $J$. foetidissima'nın de bulunduğu birçok dağ ormanı habitatı büyük ölçüde bozulmaya uğramıştır (Eler ve Çetin, 2006; Köse vd., 2018). Türün doğal rejenerasyonu; yavaş büyüme, düşük tohum canlılığı ve çimlenme sorunları nedeniyle zordur (Tilki, 2007). Buna ek olarak, ardıç meşcerelerindeki azalma, tohum yetiştirme için son derece uygun ve daha yoğun ağaç örtüsünün altında bulunan, besleyici maddeler bakımından zengin toprakların yok olmasına neden olmaktadır (Köse, 2000; Rupprecht vd., 2011). Bu durum, ardıç türlerinin hayatta kalması için ciddi bir tehdit oluşturmaktadır. Dolayısıyla, mevcut ardıç meşcerelerini korumak ve sürdürülebilirliklerini sağlamak için koruma önlemlerinin alınması gereklidir (Pinna vd., 2015).

$\mathrm{Bu}$ çalışma, Türkiye'de doğal yayılış gösteren $J$. foetidissima'nın günümüz ve gelecekteki potansiyel coğrafi dağılımını modellemeyi amaçlamaktadır. Türe ait var verisi ve çevresel değişkenler (biyoiklimsel değişkenler ve yükseklik) kullanılarak tahmin modelleri oluşturulmuş, tür dağılımları iki farklı küresel iklim değişikliği senaryosuna göre belirlenmiştir. 2041-2060 ve 2081-2100 zaman aralıklarında, SSP2 4.5 ve SSP5 8.5 senaryoları kapsamında, $J$. foetidissima'nın potansiyel dağılım alanları MaxEnt 3.4.1 aracılığıyla modellenmiştir. Türe ait günümüz ve gelecek yayılış farkının değişim analizi ile değerlendirildiği bu çalışmada aşağıda sunulan üç araştırma sorusuna yanıt aranmaktadır:

1) Hangi çevresel değişkenler $J$. foetidissima'nın günümüz ve gelecekteki potansiyel yayılışında etkilidir?

2) İklim değişikliği senaryolarına göre $J$. foetidissima'nın günümüz ve gelecekteki yayılışı nasıldır? 
3) $J$. foetidissima'nın potansiyel yayılış alanları, günümüzde ve gelecekte alansal ve konumsal olarak nasıl değişiklik göstermektedir?

Araştırmadan elde edilen bulgular çerçevesinde Türkiye'de doğal yayılış gösteren $J$. foetidissima'nın korunması ve sürdürülebilirliğinin sağlanması amacıyla gelecek stratejilerinin belirlenmesi için makine öğrenmesine dayanan bir değerlendirme yapılmıştır. Bu değerlendirme, peyzaj ölçeğinde orman türlerinin yönetimi ve korunan alanların planlanması için kullanılabilir.

\section{Materyal ve Metot}

Kokulu ardıç (Juniperus foetidissima Willd.) bu çalışmanın ana materyalini oluşturmaktadır. Her zaman yeşil, pul yapraklı, siyah üzeri mavi dumanlı üzümsü kozalaklı, 10-25 m'ye kadar boylanabilen, gençlikte piramidal, daha sonra yuvarlak tepeli bir ağaç olan ve adını odununun güzel kokulu olmasından alan, Kokulu ardıç, sıcağa, soğuğa, kuraklığa çok dayanıklıdır ve orman sınırının üzerindeki yüksekliklerde bireyleri bulunmaktadır. Ülkemizde Batı Akdeniz'de, Kuzey Ege'de, Güney Marmara'da, Batı ve Orta Karadeniz'in iç kesimlerinde, Doğu Karadeniz'in doğusunda, Orta ve Güneydoğu Toroslarda yer yer saf, çoğunlukla diğer ardıç türleri ve bölge ağaçları ile birlikte yayılış yapmaktadır (Akkemik, 2018; Mamıkoğlu ve Ergüven, 2012). Dayanıklı odunu olduğundan mobilyacılıkta, aynı zamanda park ve bahçelerde peyzaj tasarımında kullanılmaktadır (OGM, 2009).

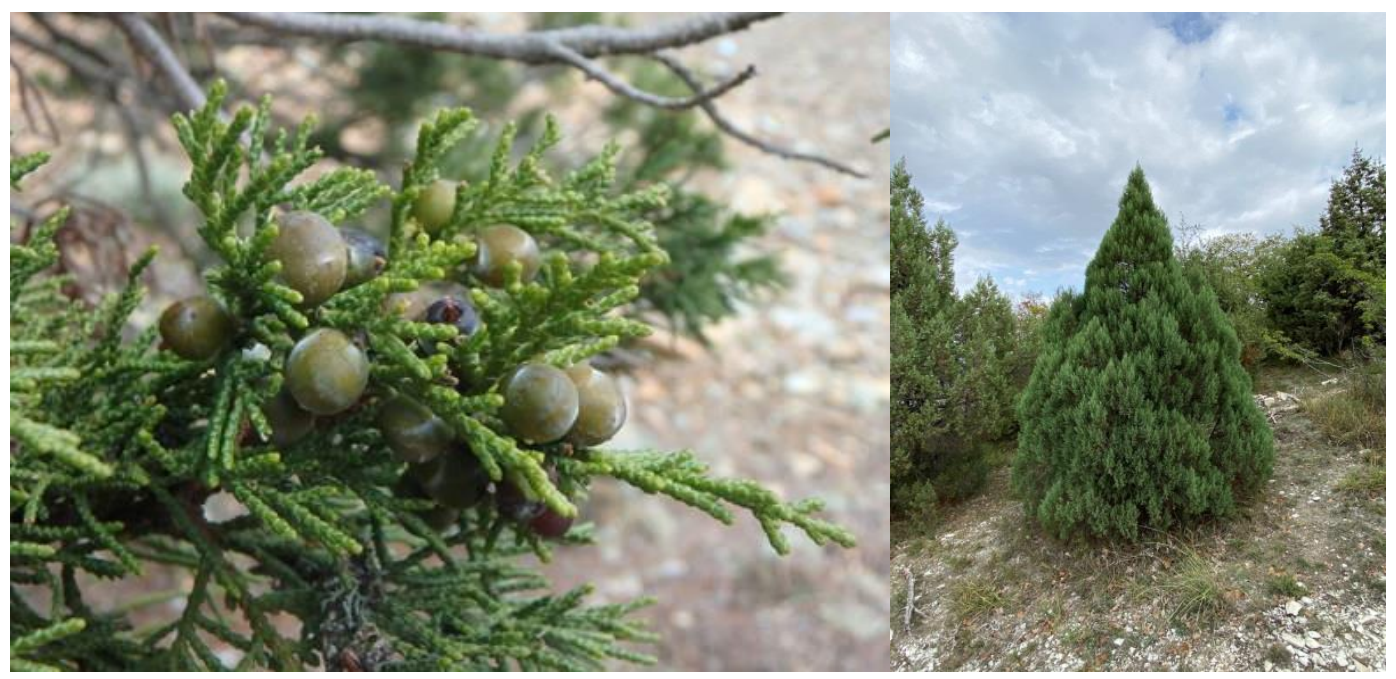

Şekil 1. Kokulu ardicın habitus, yaprak ve meyveleri

\section{https://www.inaturalist.org/photos/28405797}

\section{https://www.inaturalist.org/observations/62287359}

$\mathrm{Bu}$ çalışmada, bağıntılı niş modellemede makine öğrenimi tekniklerinden maksimum entropi algoritmasını kullanan ve çok az sayıda örneklem ile yüksek performans gösterebilen MaxEnt 3.4.1 yazılımı kullanılmıştır. MaxEnt 3.4.1 yazılımını çalıştırmak için 3 ana veri seti oluşturulmuştur. Bunlardan birincisi türe ait var verileri, ikincisi güncel yayılışı tahmin için çevresel değişkenler, üçüncüsü ise türün gelecek tahmini için belirlenen iklim modeline bağlı senaryolara ait zaman aralıklarıdır. Çalışmada var verileri olarak isimlendirilen ve türün doğal olarak coğrafi yayılış alanını temsil eden 26 noktanın koordinat bilgileri küresel biyoçeşitlilik Bilgi Sistemi (GBIF), Flora of Turkey (Davis, 1965) ve diğer literatür kaynakları (GBIF, 2020) kullanılarak belirlenmiş ve MaxEnt programının kullanabileceği “csv" formatlı dosya haline dönüştürülmüştür (Şekil 2). 


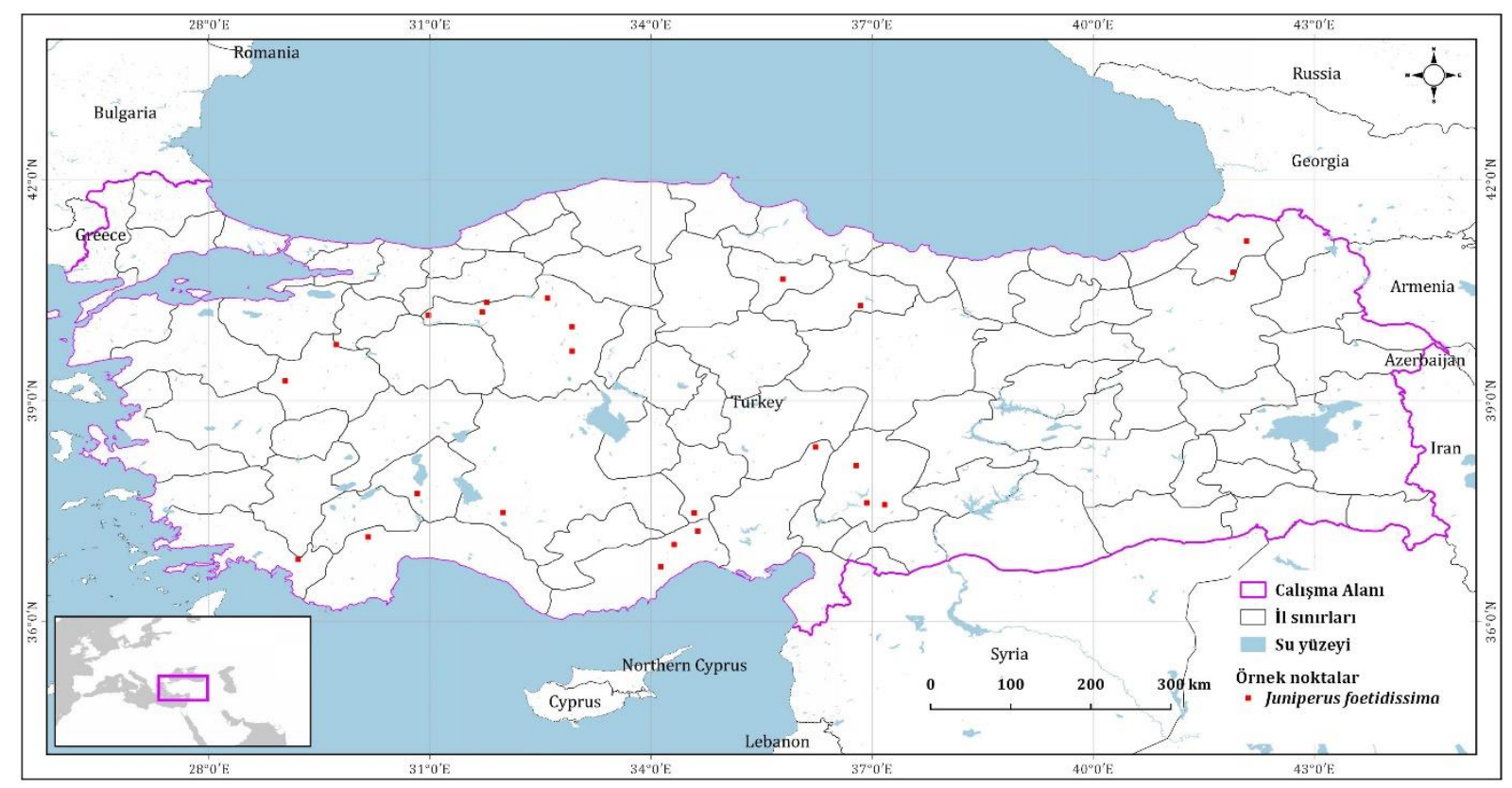

Şekil 2. Türe ait var verilerini gösteren noktaların coğrafi yayılışı

İkinci veri seti olan ve türün günümüz yayılış alanını tahmin etmek için kullanılan çevresel değişkenler (bioklimatik ve yükseklik verileri) Ocak 2020'de kullanıma sunulan WorldClim veri paylaşım sitesinden elde edilmiştir. WorldClim 2.1 versiyon olarak adlandırılan, 2.5 dakika $\left(\sim 20 \mathrm{~km}^{2}\right)$ uzamsal çözünürlüğe sahip raster veri formatındaki biyoiklimsel veriler 1970-2000 yılları arasında ölçülen minimum ve maksimum sıcaklık ortalamaları ile yıllık yağış ortalamalarından türetilmiş 19 biyoklimatik değişkeni içerir. Üçüncü veri seti olan ve türün gelecekteki yayılış alanını tahmin etmek için kullanılan, iklim modeli olarak Tokyo Üniversitesi İklim Sistemi Araştırma Merkezi önderliğinde geliştirilen, disiplinler arası araştırma modelinin altınc1 versiyonu olan MIROC6 iklim modeli seçilmiştir. CMIP6 protokolü tarafından önerilen tarihsel güneş ışınım spektrumları, sera gazı konsantrasyonları, antropojenik aerosal emisyonları ve biyokütle yakma emisyonlarını içeren MIROC6 iklim modeli denge iklim duyarlılığı (ECS) yani atmosferik CO'in iki katı olması durumunda beklenen küresel ortalama yüzeye yakın hava sıcaklığının uzun vadeli sıcaklık artış değerini $2,6^{\circ} \mathrm{C}$ olarak tahmin etmektedir. Bu modele bağl1 iklim senaryosu olarak küresel isınma için iyimser tahminleri içeren SSP2 4.5 ile en kötü durumu ortaya koyan SSP5 8.5 senaryosu ve bu senaryoların 2041-2060 ile 2081-2100 periyotları çalışmada gelecek tahminleri için kullanılmıştır.

MaxEnt programı çalıştırılmadan önce günümüz ve gelecek tahminleri için kullanılacak raster veri formatındaki biyoiklimsel değişkenler ile yükseklik verisini içeren sayısal yükseklik modeli (DEM) QGIS 3.16.1 programında kesme ve dönüştürme araçları ile çalışma alanı olarak belirlenen sınırlar dâhilinde kesilmiş ve ".asc" uzantılı dosya formatına dönüştürülmüştür. Modelin tahmin gücünü artırmak ve çoklu doğrusallık sorununu çözmek amacıyla SPSS 25 istatistik paket programında örnek noktaların biyoklimatik değişkenleri kullanılarak Pearson's korelasyon analizi yapılmış ve çoklu doğrusallık problemi çözülmüştür. Maxent 3.4.1 programı çalıştırılmadan önce örnek noktaların $\% 25$ 'inin test için ayrılmasına ve arka planda kullanılan tahmin verilerinin yazdırılmasına karar verilmiş, ayrıca hangi değişkenin tek başına veya çıkarıldığında kazancı nasıl etkilediğini belirlemek amacıyla Jackknife (çek-çıar) testi ile nokta sayısı 26 olduğu için Linear, Quadratic ve Hinge özellikleri seçilmiş, diğer ayarlar varsayılan olarak bırakılmıştır. Program modelin senaryolarında belirlenen periyotlar için sırasıyla çalıştırılmış ve ".asc" uzantılı dosya formatında günümüz ve gelecek için oluşturulan model çıktıları elde edilmiştir. MaxEnt modelinde bir türün alanda bulunma durumu 0-1 arasında bir değer ile belirlenmektedir. Değerler 1'e yaklaştıkça türün potansiyel olarak o alanda bulunma durumu artmaktadır. QGIS 3.16.1 programı kullanılarak tüm raster veriler önce raster hesaplama aracı daha sonra da raster/vektör dönüşümü fonksiyonu ile vektör veriye dönüştürülmüss, dönüşüm sırasında uygunluk değeri olarak isimlendirilen DN (Digital Number) için eşik değerleri $0=0,0-0,4=1,0,4-0,8=2$ ve $0,8-1=3$ olacak şekilde sınıflandırılmıştır. Güncel ve gelecek için oluşturulan potansiyel dağılım haritalarında yayılış alanı için eşik değer sınıflandırmasında 0 "uygun değil", 1 "az uygun", 2 "uygun" ve 3"çok uygun" alanlar olacak şekilde isimlendirilmiş ve bu sinıflandırmaya göre günümüz ve gelecek tahmini yayılış alanları $\mathrm{km}^{2}$ olarak hesaplanmıştır.

Son aşamada türün günümüz ve gelecek tahmini yayllış alanlarındaki değişimin yönünü ve büyüklüğünü belirlemek amacıyla değişim analizi uygulanmıştır Değişimlerin belirlenmesi için vektörel formattaki günümüz ile tüm zaman aralıklarındaki gelecek tahmin verilerine kesişim fonksiyonu uygulanmıştır. Kesişim sonucu oluşan verilerin öznitelik bilgisindeki uygunluk değerleri (DN) 0-0 olan alanlar uygun değil, aynı değerde kalanlar "değişim yok", bir üst sınıfa geçen değerler "kazanç", bir alt sınıfa geçen değerler "kayıp" olarak değerlendirilmiş ve kapladıkları alanlar $\mathrm{km}^{2}$ cinsinden hesaplanarak değişim haritaları oluşturulmuştur.

\section{Araştırma Sonuçları ve Tartışma}

Yöntemde belirtilen istatistik analizlerinden çoklu doğrusallık (multicollinearity) sorununu çözmek için yapılan Pearson korelasyon testi sonuçlarına göre korelasyon matrisinde $r$ değeri \pm 0.8 olan değişkenler kendi aralarında önem durumuna göre çıkarılmış ve modelin tahmin yeteneğini gücünü artıran değişkenler olarak $\mathrm{BIO} 2, \mathrm{BIO}$, $\mathrm{BIO} 5 \mathrm{BIO6}, \mathrm{BIO} 7, \mathrm{BIO}$, BIO9, BIO15, BIO18 ve yükseklik değişkenleri modelde kullanılmıştır. Modelin performansını belirlemek için Receiver 
Operating Characteristic (ROC) analizinden elde edilen ve MaxEnt program çıktısı olan Area Under the Curve (AUC) değerinden faydalanılmış ve eğitim verisi için AUC değeri 0,905 test verisi için 0,856 olarak hesaplanmıştır. Eğitim verisi için elde edilen bu değer modelin rastgele tahminden çok daha yüksek bir tahmin gücü olduğunu göstermektedir (Şekil 3).
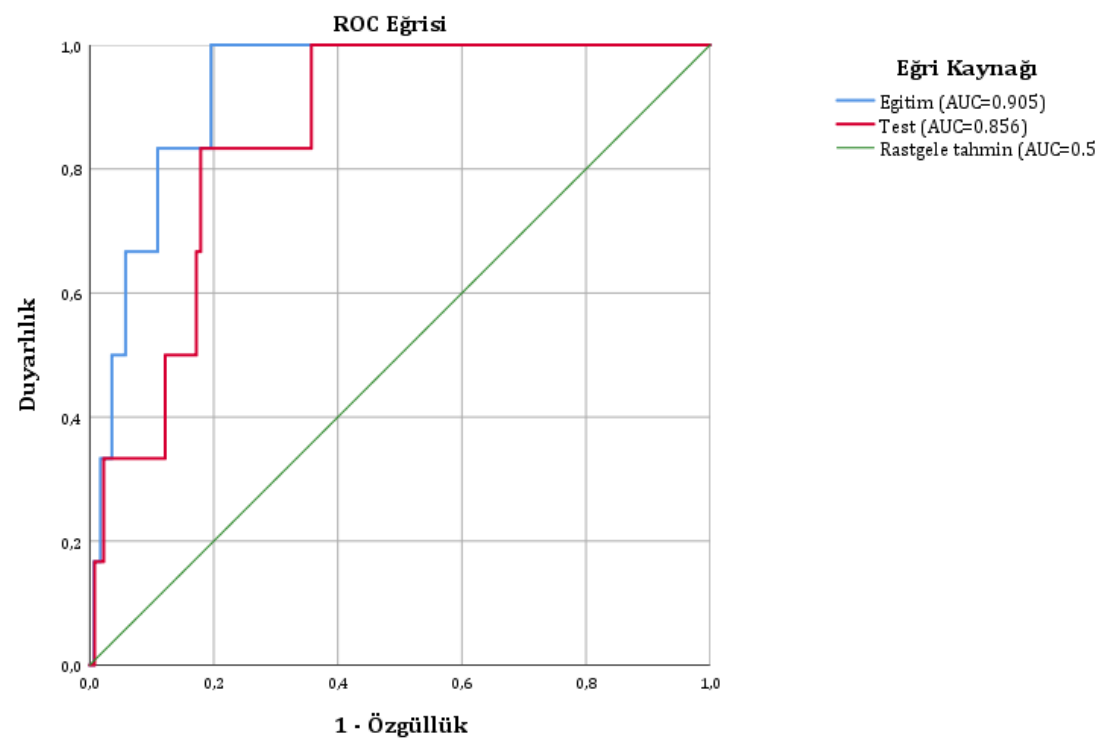

Şekil 3. Türe ait AUC grafiği

Jackknife testi sonuçlarına göre, model tek başına kullanıldığında en yüksek kazancı sağlayan çevresel değişken yükseklik değişkenidir. Bu değişkeni sırasıyla en soğuk ayın en az sıcaklığı (BIO6) ve en nemli mevsimin ortalama sicaklığ (BIO8) takip etmektedir. Modelden çıkarıldığında kazancı en çok azaltan çevresel değişken ise en soğuk ayın en az sıcaklığ (BIO6)'dır. Bu nedenle BIO6 değişkeninin diğer değişkenlerde bulunmayan en fazla bilgiye sahip olduğu düşünülmektedir (Şekil 4).

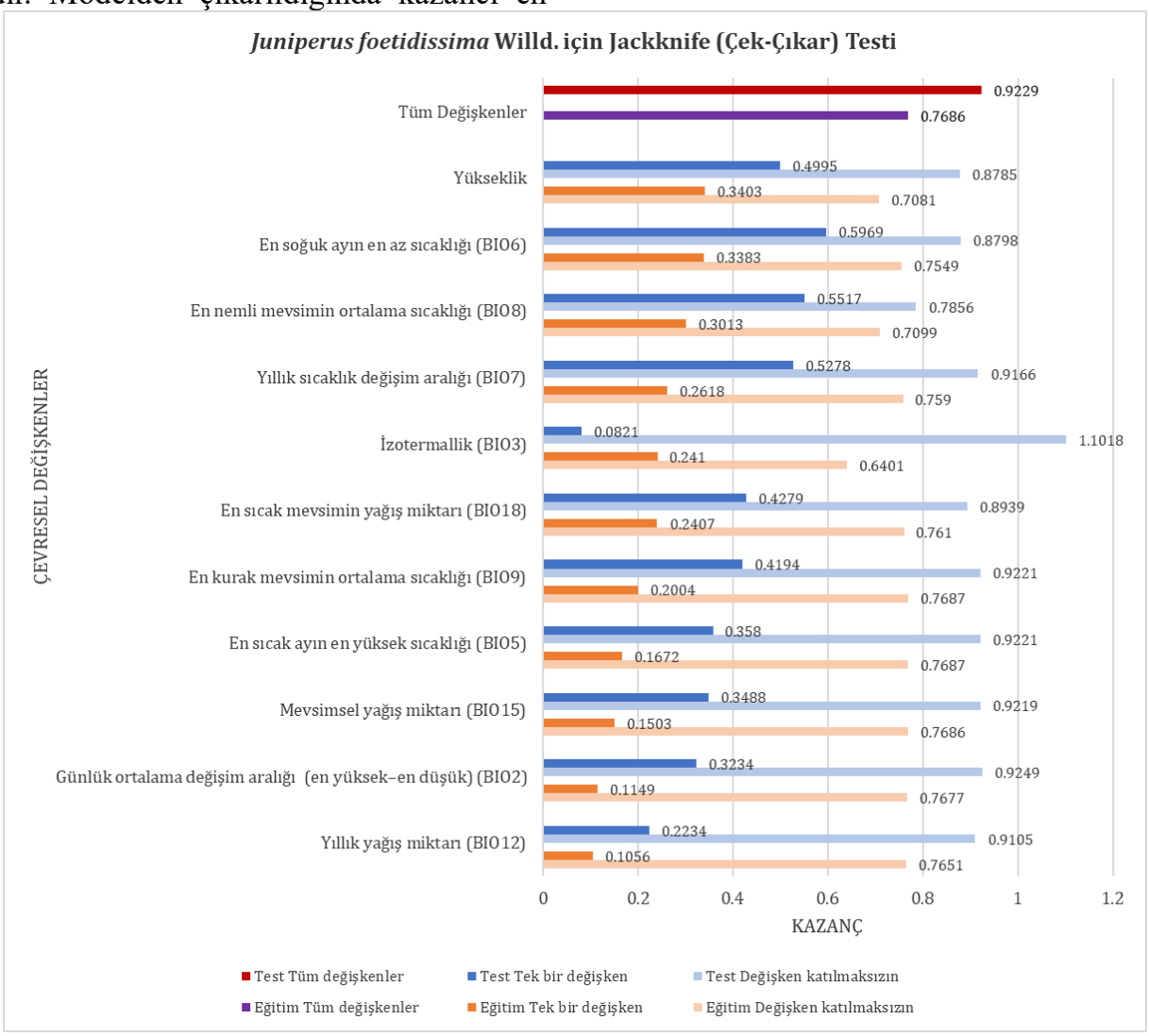

Şekil 4. Türe ait jackknife testi sonuçları

Juniperus foetidissima Willd.'nin günümüz ve gelecek potansiyel coğrafi dağılımlarına ait tahmin modelleri Şekil 5, 6 ve 7 'da verilmiştir. Üretilen model uygunluk düzeylerine göre Uygun değil (0) Az uygun (0-0,4), uygun $(0,4-0,8)$ ve çok uygun $(0,8-1)$ olmak üzere dört farklı seviyede sınıflandırılmış ve QGIS
3.16.1 programı kullanılarak haritalandırılmıştır. Elde edilen haritalarda $J$. foetidissima'nın günümüz ve gelecekteki konumsal dağılımı izlenebilmektedir. Model çıktıları sonucunda elde edilen güncel dağılım haritası incelendiğinde $J$. foetidissima'nın 


\section{Avrupa Bilim ve Teknoloji Dergisi}

doğal yayılış alanları ile yüksek oranda benzerlik gösterdiği görülmektedir.

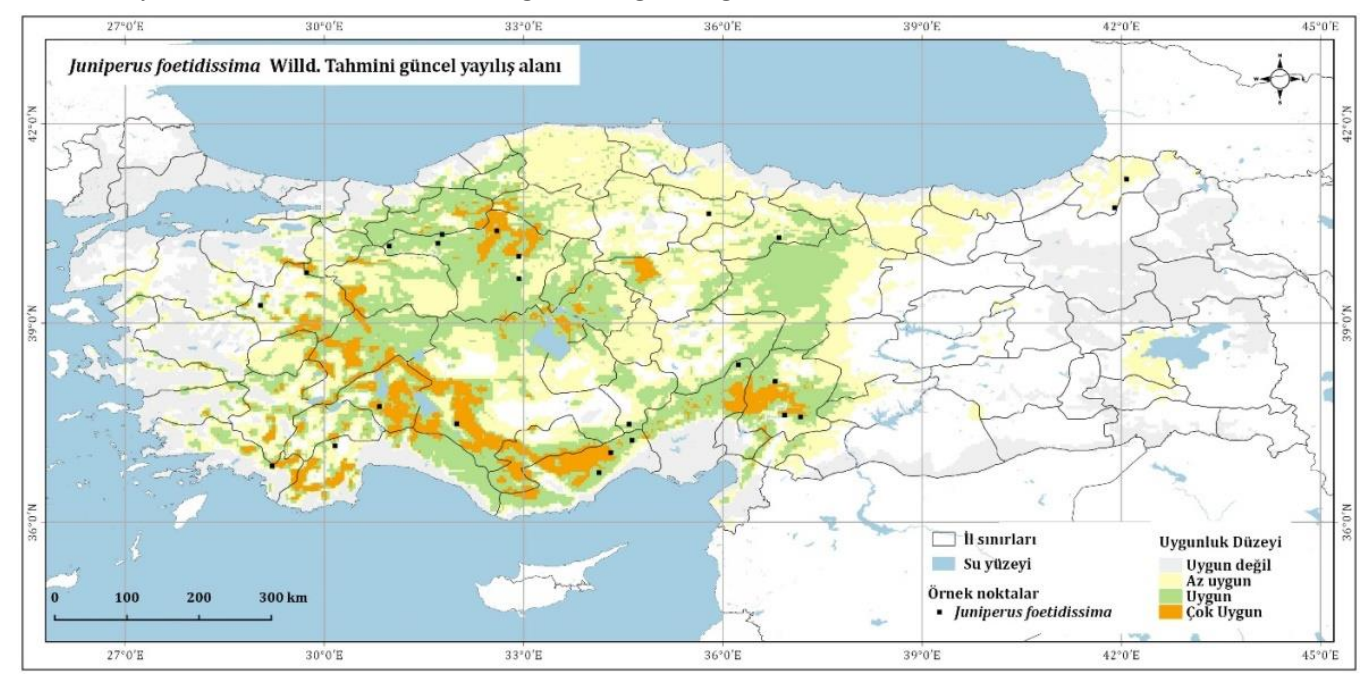

Şekil 5. Türe ait günümüz potansiyel yayılış alanı

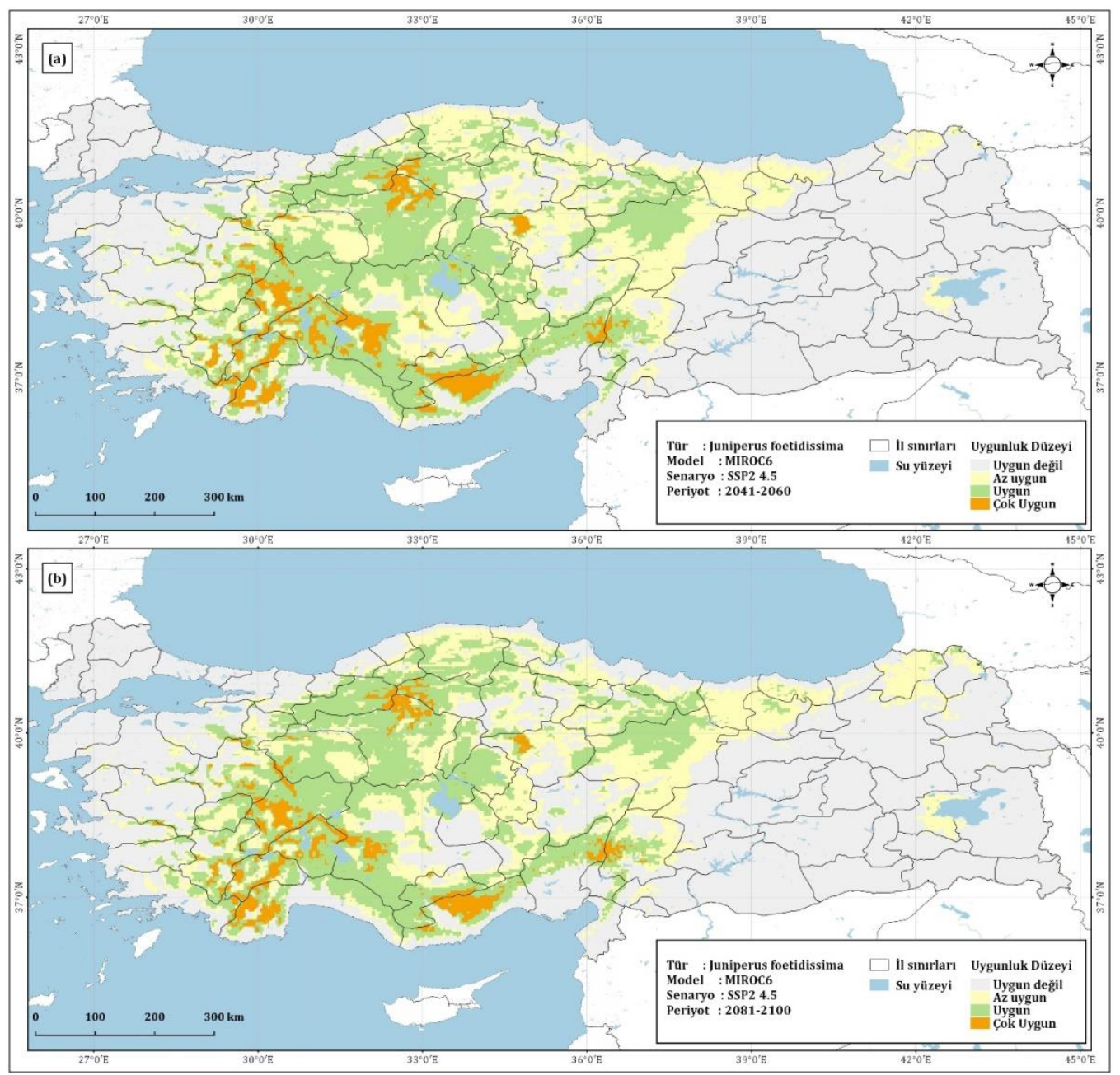

Şekil 6. Türün SSP2 4.5 iklim değişimi senaryosuna göre (a) 2041-2060 ve (b) 2081-2100 zaman aralıklarındaki potansiyel yayılışı 


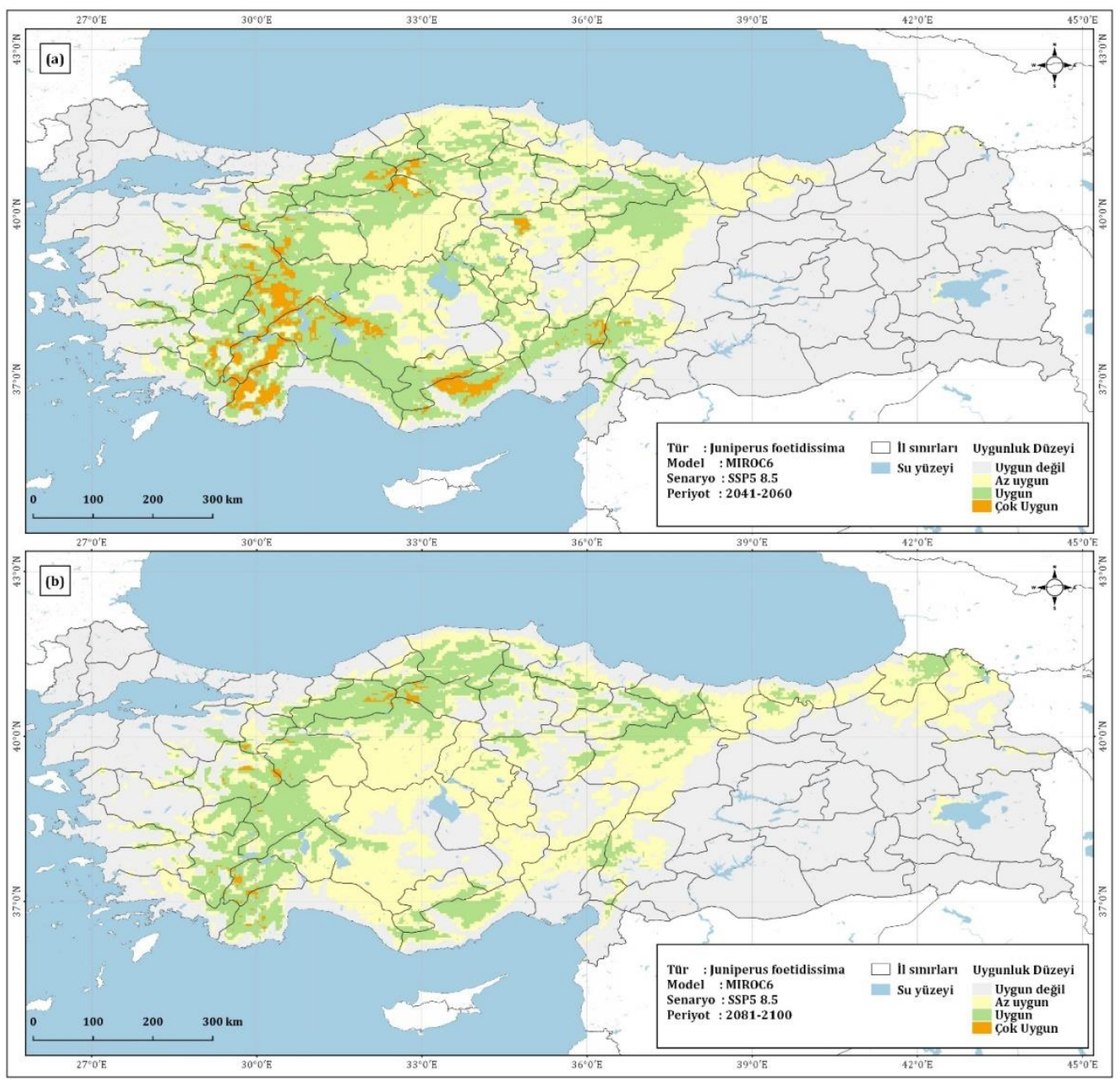

Şekil 7. Türün SSP5 8.5 iklim değiş̧imi senaryosuna göre (a) 2041-2060 ve (b) 2081-2100 zaman aralıklarındaki potansiyel yayılış1

Türün gelecek senaryolarına göre potansiyel yayılışı incelendiğinde (Tablo 1) SSP2 4.5 senaryosunda dağglım alanları içerisinde çok uygun olan alanların 2041-2060 ve 2081-2100 zaman aralıklarında $28523 \mathrm{~km}^{2}$ ye kadar düşeceği, SSP5 8.5 senaryosunda ise bu düşüşün $4153 \mathrm{~km}^{2}$ 'ye kadar olacağ öngörülmektedir. Türün dağılım alanları içerisinde uygun alanların ise her iki senaryo ve yıl zaman aralıklarında da azalma yönünde eğilim göstereceği tahmin edilmektedir

Tablo 1. Türün dă̆glım alanlarl $\left(\mathrm{km}^{2}\right)$

\begin{tabular}{llllll}
\hline Uygunluk Düzeyi & Güncel & SSP2 2041-2060 & SSP2 2081-2100 & SSP5 2041-2060 & SSP5 2081-2100 \\
\hline Uygun Değil & 427622 & 425440 & 425357 & 430066 & 445147 \\
Az uygun & 171835 & 164017 & 167226 & 172720 & 220512 \\
Uygun & 139839 & 157760 & 159349 & 152796 & 110642 \\
Çok uygun & 41159 & 33237 & 28523 & 24873 & 4153 \\
TOPLAM & 780454 & 780454 & 780454 & 780454 & 780454
\end{tabular}

Türe ait SSP2 4.5 ve SSP5 8.5 senaryolar1 2041-2060 ve 2081-2100 zaman aralıklarına ilişkin yapılan değişim analizi haritaları Şekil 8 ve 9'da değişim analizine ait sayısal değerler ise Tablo 2'de gösterilmektedir. Şekil 8 ve 9'da, $J$. foetidissima'nın SSP2 4.5 ve SSP5 8.5 iklim değişikliği senaryolarına göre 2041-2060 ve 2081-2100 zaman aralıkları için modellenen potansiyel dağılım alanlarında değişimin büyüklüğü ve yönü gösterilmişti 
Avrupa Bilim ve Teknoloji Dergisi

Tablo 2. Değişim analizi sonuçlarl $\left(\mathrm{km}^{2}\right)$

\begin{tabular}{ccccc}
\hline Değişim & SSP2 2041-2060 & SSP2 2081-2100 & SSP5 2041-2060 & SSP5 2081-2100 \\
\hline Kazanç & 65224 & 74771 & 74778 & 74736 \\
Kayıp & 59353 & 77645 & 94520 & 174876 \\
Değişiklik Yok & 251497 & 230710 & 210676 & 142592 \\
Uygun Değil & 404381 & 397329 & 400480 & 388250 \\
TOPLAM & 780454 & 780454 & 780454 & 780454
\end{tabular}

Tablo 2'e göre, SSP2 4.5 senaryosu 2041-2060 zaman aralığında $65224 \mathrm{~km}^{2}$ 'lik kazanç alanı hesaplanırken, $59353 \mathrm{~km}^{2}$ kayıp olarak gösterilmiştir. SSP2 4.5 senaryosu 2081-2100 zaman aralığında ise kazanç alanları $74771 \mathrm{~km}^{2}$, kayıp alanları ise $277645 \mathrm{~km}^{2}$ olarak hesaplanmıştır. SSP5 8.5 senaryosu 2041 2060 zaman aralığında $74778 \mathrm{~km}^{2}$ 'lik kazanç alanı hesaplanırken, $94520 \mathrm{~km}^{2}$ lik alan ise kayı olarak hesaplanmıştır

. SSP5 8.5 senaryosu 2081-2100 zaman aralığında kazanç alanlar $74736 \mathrm{~km}^{2}$, kayıp alanlar ise $174876 \mathrm{~km}^{2}$ olarak hesaplanmıştır.

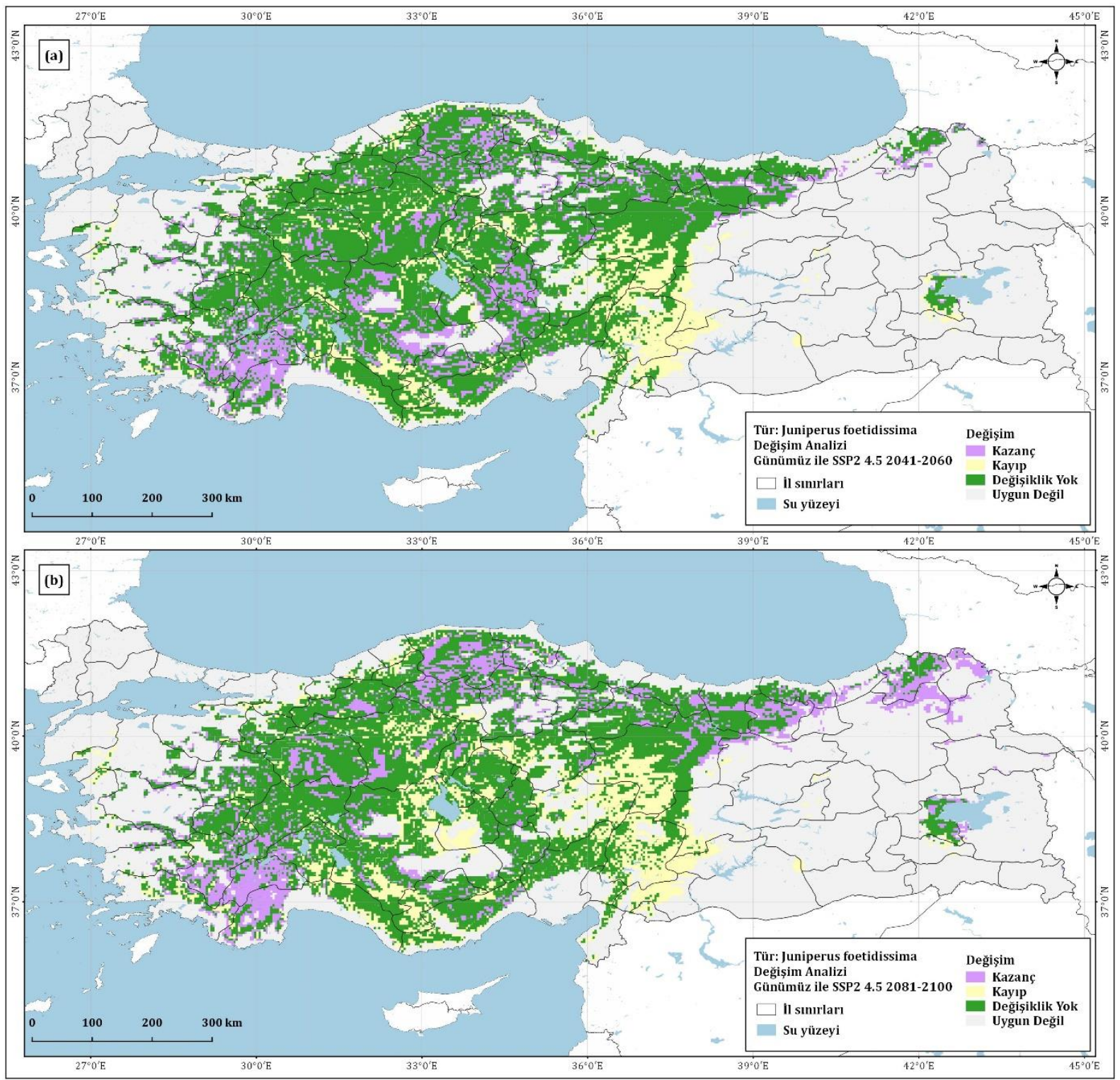

Şekil 8. Türün SSP2 4.5 iklim değişimi senaryosuna göre (a) 2041-2060 ve (b) 2081-2100 zaman aralıklarındaki değişimi 


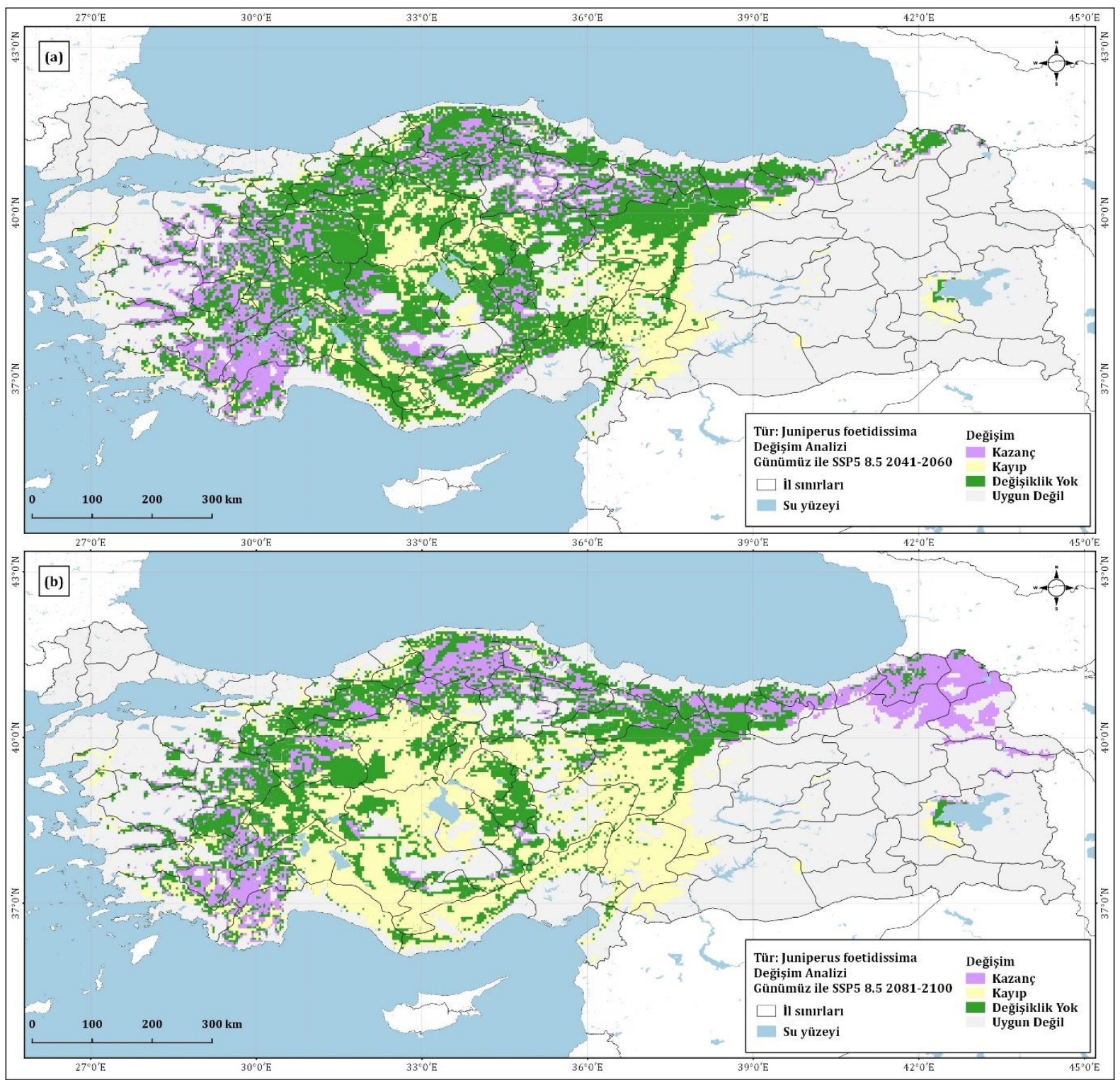

Şekil 9. Türün SSP2 8.5 iklim değişimi senaryosuna göre (a) 2041-2060 ve (b) 2081-2100 zaman aralıklarındaki değişimi

İklim değişikliğinin çeşitli türler üzerindeki etkilerini araştıran birçok çalışma, iklimin coğrafi dağılım aralıkları üzerinde önemli bir etkisi olduğunu göstermiştir (Arslan vd., 2020; Bouahmed vd., 2019; Ferrarini vd., 2019; Wu vd., 2021). Türlerin, iklim koşullarına nasıl tepki verdiğinin anlaşılmasında maksimum entropinin (MaxEnt) rolü büyüktür (Feng vd., 2019). MaxEnt ile yapılan modelleme çalışmaları, biyolojik çeşitliliğin korunmasının yanı sıra ekolojik açıdan türlerin sürdürülebilirliği çerçevesinde hazırlanan çevresel politikalara katkı sağlamaktadır (Li vd., 2020; Remya vd., 2015). Bu çalışmada, MaxEnt kullanılarak Juniperus foetidissima'nın günümüz ve gelecekteki potansiyel coğrafi yayılışı SSP2 4.5 ve SSP5 8.5 senaryoları ile modellenmiştir. Bulgular, J. foetidissima'nın habitat uygunluğunun her iki senaryoya göre önemli oranda düşeceğine işaret etmektedir. Özellikle SSP2 2081-2100 ve SSP5 2081-2100 senaryoları, bu düşüşün önemli miktarda olacağını vurgulamaktadır. Bu durum da, habitat uygunluğu azalan türün, gelecekte iklim değişikliğinin olumsuz etkilerine karşı direnç gösteremeyeceğini ve tehlike altına gireceğini göstermektedir. Dolayısıyla, J. foetidissima'nın ekolojik olarak sürdürülebilirliği için peyzaj yönetimi kapsamında koruma faaliyetleri başlatılması gereği açıktır.
Biyoiklimsel değişkenler ile yüksekliğin öngörücü (predictor) olarak değerlendirildiği bu çalışmada, $J$. foetidissima'nın yüksek rakımdaki dağlık bölgeleri tercih etme eğiliminde olduğu dikkat çekmektedir. Her bir tahmin değişkeninin göreceli katkısını gösteren Jackknife (çek-çıkar) testi sonuçları, yüksekliğin en önemli çevresel değişken olduğunu doğrulamaktadır. Ayrıca, yükseklik kadar önemli olmasa da, J. foetidissima'nın yayılışında en soğuk ayın en az sıcaklığı (BIO6) ve en nemli mevsimin ortalama sıcaklığ (BIO8) da etkili diğer çevresel değişkenlerdir. Bu çalışmada, her bir iklim değişkeninin modele katkı yüzdesi karşılaştırılmış, çoklu doğrusallık (multi-collinearity) etkilerini ortadan kaldırmak için Pearson korelasyon katsayısının yardımcı olduğu gözlemlenmiştir. MaxEnt modelinin kararlılığını doğrulamak için AUC değeri kullanılmıştır. Hesaplanan AUC (eğitim) değerinin 0,905 olması, sonuçların önemli olduğuna işaret etmektedir. Tahmin doğruluğunu ifade eden ROC eğrisi, modelin simülasyon gücünün çok yüksek olduğunu (mükemmel kategoride) desteklemektedir.

Değişim analizi sonuçları incelendiğinde, J. foetidissima'nın habitat uygunluğunda SSP2 2041-2060 ile SSP2 2081-2100 arasında kazanç miktarının arttı̆̆1, SSP5 2041-2060 ile SSP5 2081-2100 arasındaki kazanç miktarının ise düştüğü 
gözlemlenmiştir. Habitat kaybı miktarı ise her iki senaryoya göre de marjinal olarak artmıştır. Habitat kaybı miktarında, SSP5 2041-2060 ile SSP5 2081-2100 arasındaki değişim daha yüksektir. Sonuç olarak, habitat uygunluğundaki alansal kayıp, kazanç miktarından daha fazladır. $\mathrm{Bu}$ durum da, $J$. foetidissima'nın potansiyel yayılışının gelecekte azalacağını açık bir şekilde ortaya koymaktadır.

J. foetidissima'nın doğal rejenarasyon zorluğu, orman tahribatı sonucundaki bozunumu ve orman alanlarında yasak otlatma sonucunda zarar görmesi, iklim koşullarının da olumsuz etkisiyle gelecekte daha ciddi bir baskı altına girmesine neden olabilir. İklim değişikliğinin hızı henüz açıklanamamış olsa da, değişen koşullar habitat kaybında göz ardı edilmeyecek bir ivmelenmeye yol açabilir. Dolayısıyla, J. foetidissima zaman içerisinde relikt türler arasında yer alabilir.

Gelecekteki iklim koşullarına bağlı habitat değişiklikleri, tehdit altındaki türlerin bulunma potansiyeli olan alanları korumak için uygun adaptasyon stratejileri gerektirir (Muller vd., 2019). İklim değişikliğinin olası olumlu ve olumsuz etkileri dikkatle ele alınmalı ve uygun adaptasyon stratejilerinin uygulanması için bir firsat olarak görülmelidir. Örneğin, bazı türlerin uygun yaşam alanlarındaki potansiyel artış, iklim değişikliğinden kaynaklanan çeşitli baskılara dayanmalarına yardımcı olacaktır (Moukrim vd., 2019). Ya da bu durumun aksine, adaptasyon direnci düşük olan türler yok olma tehlikesi ile karşı karşıya kalacaktır (Wiens, 2016). Dolayısıyla, bu çalışmada $J$. foetidissima'nın iklim değişikliklerine adaptasyon direncinin yüksek olmaması, tür koruma çalışmalarına dâhil edilmesi gerektiğini göstermektedir. Bulgular bölümünde sunulan potansiyel yayılış haritaları, peyzaj ölçeğinde yapılan koruma çalışmalarında stratejik adımların belirlenmesi kapsamında önemli katkılar sağlayacak niteliktedir.

\section{Sonuç}

İklim değişikliğinin olumsuz etkilerini minimize etmek için türlerin coğrafi dağılım varyasyonuna ilişkin doğru tahminler elde etmek, koruma biyolojisinde önemli bir konu haline gelmiştir (Naudiyal vd., 2021). Bu çalışmanın sonuçları, değişen iklimsel koşulların Juniperus foetidissima Willd.'yi olumsuz etkileyeceğini göstermektedir. Yapılan projeksiyonlara göre, her iki zaman aralığında da (2041-2060 ve 2081-2100) J. foetidissima'nın habitat uygunluğunun önemli miktarda azalacağ1 sonucuna ulaşılmıştır. İklim senaryolarına göre (SSP2 4.5 ve SSP5 8.5), mevcut tür oluşumu için çok yüksek uygunluk gösteren bölgelerin büyük bir bölümünün gelecekte orta ile düşük uygunlukta ortaya çıkacağı tahmin edilmiştir. $\mathrm{Bu}$ çalışmada, yükseklik verisi iklim senaryolarına entegre edilerek kapsamlı bir değerlendirme yapılmıştır. Maksimum entropi modeli yüksekliğin en önemli çevresel değişken olduğunu göstermiş, çok yüksek AUC değeri ise modellemenin başarı ile tamamlandığını kanıtlamıştır. Türkiye'de iklim değişikliğinin, $J$. foetidissima türü üzerindeki etkisinin değerlendirilmesinde güvenirliği yüksek bilgiler sunulmuştur. Sonuç olarak; bu çalışmanın bulguları, orman ekosisteminde doğa koruma ve ekosistem hizmetlerinin sürdürülebilirliği için peyzaj yönetimi çerçevesinde rasyonel ve geniş ölçekli adaptasyon stratejilerinin oluşturulmasına yardımcı olabilir.

Bu çalışmadan elde edilen sonuçlar, günümüzde $J$. foetidissima'nın saf ya da diğer türlerle birlikte oluşturduğu doğal ormanlarda coğrafik varyasyon çalışmalarının süratle başlatılmalısı ve popülasyonlar arası ve popülasyon içi genetik çeşitlilik çalışmalarının yapılması gerektiğine işaret etmektedir.
Türün iklim değişikliği ve özellikle de küresel ısınmaya bağlı olarak gelecekte yaşanabilecek olası kuraklığa dayanıklı popülasyonları ve genotipleri bilimsel araştırmalarla ortaya konulmalıdır. Buna ek olarak, türün in-situ ve ex-situ gen koruma alanları belirlenmeli ve tohum bahçeleri kurulmalıdır. Özellikle gelecekte yayılış gösterebileceği muhtemel alanlarda farklı orijinlerden alınacak genetik materyallerle adaptasyon çalışmalarına başlanması türün sürdürülebilirliği ve koruma stratejisi açısından önemli bir yaklaşım olacaktır.

$\mathrm{Bu}$ çalışmada, J. foetidissima'nın biyolojik gereksinimleri dikkate alınmamıştır. Gelecek modellemelerde, türlerin ekolojik ihtiyaçları çalışmaya dahil edilerek tahmin modelinin kapsamı genişletilebilir ve habitatların dengede olup olmadıkları daha detaylı olarak belirlenebilir. Böylece, potansiyel uygun aralıkların belirlenmesi için daha güçlü referanslar oluşturulabilir. Benzer şekilde, arazi örtüsü/alan kullanım (AÖ/AK) değişimi bu çalışmada değerlendirilmemiştir. Bundan sonraki çalışmalar, $\mathrm{AÖ} / \mathrm{AK}$ değişimini iklim modellemesine entegre edebilir.

\section{Kaynakça}

Abdelaal, M., Fois, M., Fenu, G., \& Bacchetta, G. (2019). Using MaxEnt modeling to predict the potential distribution of the endemic plant Rosa arabica Crép. In Egypt. Ecological Informatics, 50, 68-75. https://doi.org/10.1016/j.ecoinf.2019.01.003.

Akkemik, Ü. (2018). Türkiye'nin Doğal-Egzotik Ağaç ve Çalıları. T. C. Orman ve Su İşleri Bakanlığı Orman Genel Müdürlüğü, Ankara.

Akyol, A., Örücü, Ö. K. (2019). İklim değişimi senaryoları ve tür dağılım modeline göre Kızılcık türünün (Cornus mas L.) odun dışı orman ürünleri kapsamında değerlendirilmesi. Avrupa Bilim ve Teknoloji Dergisi, 17, 224-233. https://doi.org/10.31590/ejosat.615019.

Arslan, E. S., Akyol, A., Örücü, Ö. K., \& Sarıkaya, A. G. (2020). Distribution of rose hip (Rosa canina L.) under current and future climate conditions. Regional Environmental Change, 20(3), 107. https://doi.org/10.1007/s10113-02001695-6.

Barve, N., Barve, V., Jiménez-Valverde, A., Lira-Noriega, A., Maher, S. P., Peterson, A. T., Soberón, J., \& Villalobos, F. (2011). The crucial role of the accessible area in ecological niche modeling and species distribution modeling. Ecological Modelling, 222(11), 1810-1819. https://doi.org/10.1016/j.ecolmodel.2011.02.011.

Bouahmed, A., Vessella, F., Schirone, B., Krouchi, F., \& Derridj, A. (2019). Modeling Cedrus atlantica potential distribution in North Africa across time: New putative glacial refugia and future range shifts under climate change. Regional Environmental Change, 19(6), 16671682. https://doi.org/10.1007/s10113-019-01503-w.

Chakraborty, A., Joshi, P. K., \& Sachdeva, K. (2016). Predicting distribution of major forest tree species to potential impacts of climate change in the central Himalayan region. Ecological Engineering, 97, 593-609. https://doi.org/10.1016/j.ecoleng.2016.10.006.

Chase, J. M., \& Leibold, M. A. (2003). Ecological Niches: Linking Classical and Contemporary Approaches. University of Chicago Press.

Choudhary, J. S., Mali, S. S., Fand, B. B., \& Das, B. (2019). Predicting the invasion potential of indigenous restricted mango fruit borer, Citripestis eutraphera (Lepidoptera: Pyralidae) in India based on MaxEnt modelling. Current 
Science, $116(4)$

636-642. https://doi.org/10.18520/cs/v116/i4/636-642.

Damschen, E. I., Harrison, S., \& Grace, J. B. (2010). Climate change effects on an endemic-rich edaphic flora: Resurveying Robert H. Whittaker's Siskiyou sites (Oregon, USA). Ecology, 91(12), 3609-3619. https://doi.org/10.1890/09-1057.1.

Davis, P. H. (1965). Flora of Turkey and The East Aegean Islands-I: Vol. One (P. H. David, Ed.). Edinburgh University Press.

Du, Z., He, Y., Wang, H., Wang, C., \& Duan, Y. (2021). Potential geographical distribution and habitat shift of the genus Ammopiptanthus in China under current and future climate change based on the MaxEnt model. Journal of Arid Environments, 184, 104328. https://doi.org/10.1016/j.jaridenv.2020.104328.

Dyderski, M. K., Paź, S., Frelich, L. E., \& Jagodziński, A. M. (2018). How much does climate change threaten European forest tree species distributions? Global Change Biology, 24(3), 1150-1163. https://doi.org/10.1111/gcb.13925.

Eler, Ü., \& Çetin, A. (2006). Ardıç tohumunun çimlendirilme olanaklar1. Süleyman Demirel Üniversitesi Orman Fakültesi Dergisi Seri: A, O(1), 33-45.

Elith, J., Graham, C. H., A, R. P., Dudík, M., Ferrier, S., Guisan, A., ... Zimmermann, N. E. (2006). Novel methods improve prediction of species' distributions from occurrence data. Ecography, 29(2), 129-151. https://doi.org/10.1111/j.2006.0906-7590.04596.x.

Elith, J., Phillips, S. J., Hastie, T., Dudik, M., Chee, Y. E., \& Yates, C. J. (2011). A statistical explanation of MaxEnt for ecologists. Diversity and Distributions, 17(1), 43-57. https://doi.org/10.1111/j.1472-4642.2010.00725.x.

Feng, X., Park, D. S., Walker, C., Peterson, A. T., Merow, C., \& Papeş, M. (2019). A checklist for maximizing reproducibility of ecological niche models. Nature Ecology \& Evolution, 3(10), 1382-1395. https://doi.org/10.1038/s41559-019-0972-5.

Ferrarini, A., Alsafran, M. H. S. A., Dai, J., \& Alatalo, J. M. (2019). Improving niche projections of plant species under climate change: Silene acaulis on the British Isles as a case study. Climate Dynamics, 52(3), 1413-1423. https://doi.org/10.1007/s00382-018-4200-9.

Friend, A. D., Lucht, W., Rademacher, T. T., Keribin, R., Betts, R., Cadule, P., ... Woodward, F. I. (2014). Carbon residence time dominates uncertainty in terrestrial vegetation responses to future climate and atmospheric CO2. Proceedings of the National Academy of Sciences, 111(9), 3280-3285. https://doi.org/10.1073/pnas.1222477110.

GBIF (2020). Global Biodiversity Information Facility. Juniperus foetidissima Willd. in GBIF Secretariat. GBIF Backbone Taxonomy. Checklist dataset www.gbif.org, Erişim tarihi: 12.12.2020.

IPCC (2014). Climate Change 2014: Synthesis Report. Contribution of Working Groups I, II and III to the Fifth Assessment Report of the Intergovernmental Panel on Climate Change (s. 151). Geneva, Switzerland.

Kaky, E., \& Gilbert, F. (2019). Assessment of the extinction risks of medicinal plants in Egypt under climate change by integrating species distribution models and IUCN Red List criteria. Journal of Arid Environments, 170, 103988. https://doi.org/10.1016/j.jaridenv.2019.05.016.

Kariyawasam, C. S., Kumar, L., \& Ratnayake, S. S. (2019). Invasive Plants Distribution Modeling: A Tool for
Tropical Biodiversity Conservation With Special Reference to Sri Lanka. Tropical Conservation Science, 12 , 1940082919864269. https://doi.org/10.1177/1940082919864269.

Köse, H. (2000). Doğal Bitki Örtüsünde Bulunan Bazı Odunsu Peyzaj Bitkilerinin Tohum Çimlendirme Yöntemleri Üzerinde Araştırmalar III. Juniperus oxycedrus L. (Katran ardic1), 10(2), 88-100.

Köse, N., Okan, T., \& Akkemik, Ü. (2018). Understanding the Impacts of Illegal Logging in Turkey: A Case Study on Junipers in Eskişehir. Baltic Forestry, 24(1), 109-116.

Le Breton, T. D., Zimmer, H. C., Gallagher, R. V., Cox, M., Allen, S., \& Auld, T. D. (2019). Using IUCN criteria to perform rapid assessments of at-risk taxa. Biodiversity and 28(4), 863-883. https://doi.org/10.1007/s10531-019-01697-9.

Li, G., Huang, J., Guo, H., \& Du, S. (2020). Projecting species loss and turnover under climate change for 111 Chinese tree species. Forest Ecology and Management, 477, 118488. https://doi.org/10.1016/j.foreco.2020.118488.

Mamıkoğlu, N. G., \& Ergüven, E. (2012). Türkiye'nin Ağaçları ve Çalıları. NTV yayınları.

Manish, K., Telwala, Y., Nautiyal, D. C., \& Pandit, M. K. (2016). Modelling the impacts of future climate change on plant communities in the Himalaya: A case study from Eastern Himalaya, India. Modeling Earth Systems and Environment, 2(2), 92. https://doi.org/10.1007/s40808016-0163-1.

Miller, J. (2010). Species Distribution Modeling. Geography Compass, 4(6), 490-509. https://doi.org/10.1111/j.17498198.2010.00351.x.

Mod, H. K., Scherrer, D., Luoto, M., \& Guisan, A. (2016). What we use is not what we know: Environmental predictors in plant distribution models. Journal of Vegetation Science, 27(6), 1308-1322. https://doi.org/10.1111/jvs.12444.

Moukrim, S., Lahssini, S., Rhazi, M., Alaoui, H. M., Benabou, A., Wahby, I., ... Rhazi, L. (2019). Climate change impacts on potential distribution of multipurpose agroforestry species: Argania spinosa (L.) Skeels as case study. Agroforestry Systems, 93(4), 1209-1219. https://doi.org/10.1007/s10457-018-0232-8.

Muller, J. J., Nagel, L. M., \& Palik, B. J. (2019). Forest adaptation strategies aimed at climate change: Assessing the performance of future climate-adapted tree species in a northern Minnesota pine ecosystem. Forest Ecology and Management, 451, 117539. https://doi.org/10.1016/j.foreco.2019.117539.

Naudiyal, N., Wang, J., Ning, W., Gaire, N. P., Peili, S., Yanqiang, W., ... Ning, S. (2021). Potential distribution of Abies, Picea, and Juniperus species in the sub-alpine forest of Minjiang headwater region under current and future climate scenarios and its implications on ecosystem services supply. Ecological Indicators, 121, 107131. https://doi.org/10.1016/j.ecolind.2020.107131.

Ncube, B., Shekede, M. D., Gwitira, I., \& Dube, T. (2020). Spatial modelling the effects of climate change on the distribution of Lantana camara in Southern Zimbabwe. Applied Geography, 117, 102172 https://doi.org/10.1016/j.apgeog.2020.102172.

OGM (2009). Ormanlarımızda Yayılış Gösteren Asli Ağaç Türleri. Orman Atlası. Orman Genel Müdürlüğ̈̈: Ankara.

Pearson, R. G., Raxworthy, C. J., Nakamura, M., \& Townsend Peterson, A. \%J J. of biogeography. (2007). Predicting species distributions from small numbers of occurrence 
records: A test case using cryptic geckos in Madagascar. 34(1), 102-117.

Peterson, A. T., Papes, M., \& Eaton, M. (2007). Transferability and model evaluation in ecological niche modeling: A comparison of GARP and Maxent. Ecography, 30(4), 550-560. 7590.05102.x.

Peterson, A. Townsend, Soberón, J., Pearson, R. G., Anderson, R. P., Martínez-Meyer, E., Nakamura, M., \& Araújo, M. B. (2011). Ecological Niches and Geographic Distributions (MPB-49). Princeton University Press.

Phillips, S. J., Anderson, R. P., \& Schapire, R. E. (2006). Maximum entropy modeling of species geographic distributions. Ecological Modelling, 190(3), 231-259. https://doi.org/10.1016/j.ecolmodel.2005.03.026.

Pinna, M. S., Cañadas, E. M., Fenu, G., \& Bacchetta, G. (2015). The European Juniperus habitat in the Sardinian coastal dunes: Implication for conservation. Estuarine, Coastal and Shelf Science, 164, 214-220. https://doi.org/10.1016/j.ecss.2015.07.032.

Prevéy, J. S., Parker, L. E., \& Harrington, C. A. (2020). Projected impacts of climate change on the range and phenology of three culturally-important shrub species. PLOS ONE, 15(5), e0232537. https://doi.org/10.1371/journal.pone.0232537.

Rana, S. K., Rana, H. K., Luo, D., \& Sun, H. (2020). Estimating climate-induced 'Nowhere to go' range shifts of the Himalayan Incarvillea Juss. Using multi-model median ensemble species distribution models. Ecological Indicators, https://doi.org/10.1016/j.ecolind.2020.107127.

Regos, A., Gagne, L., Alcaraz-Segura, D., Honrado, J. P., \& Domínguez, J. (2019). Effects of species traits and environmental predictors on performance and transferability of ecological niche models. Scientific Reports, 9(1), 4221. https://doi.org/10.1038/s41598-01940766-5.

Remya, K., Ramachandran, A., \& Jayakumar, S. (2015). Predicting the current and future suitable habitat distribution of Myristica dactyloides Gaertn. Using MaxEnt model in the Eastern Ghats, India. Ecological Engineering, 82, 184-188. https://doi.org/10.1016/j.ecoleng.2015.04.053.

Rupprecht, F., Oldeland, J., \& Finckh, M. (2011). Modelling potential distribution of the threatened tree species Juniperus oxycedrus: How to evaluate the predictions of different modelling approaches? Journal of Vegetation Science, 22(4), 647-659. https://doi.org/10.1111/j.16541103.2011.01269.x.

Scherrer, D., \& Guisan, A. (2019). Ecological indicator values reveal missing predictors of species distributions. Scientific Reports, $\quad 9(1), \quad 3061$. https://doi.org/10.1038/s41598-019-39133-1.

Silva, J. L. S. e, Cruz-Neto, O., Peres, C. A., Tabarelli, M., \& Lopes, A. V. (2019). Climate change will reduce suitable
Caatinga dry forest habitat for endemic plants with disproportionate impacts on specialized reproductive strategies. PLOS ONE, 14(5), e0217028. https://doi.org/10.1371/journal.pone.0217028.

Stocker, T. F., Qin, D., Plattner, G. K., Tignor, M., Allen, S. K. , Boschung, J., Nauels, A. , Midgley, P. M., Bex, V., \& Xia, Y. (2014). IPCC, 2013: climate Change 2013: the Physical Science Basis. In: Working Group I Contribution to the IPCC 5th Assessment Report, IPCC. Cambridge University Press, Cambridge, United Kingdom and New York, NY, USA, p. 1535.

Tilki, F. (2007). Preliminary results on the effects of various pretreatments on seed germination of Juniperus oxycedrus L. Seed Science and Technology, 35(3), 765-770. https://doi.org/10.15258/sst.2007.35.3.25.

Wan, J. Z., Wang, C. J., \& Yu, F. H. (2017). Spatial conservation prioritization for dominant tree species of Chinese forest communities under climate change. Climatic Change, 144(2), 303-316. https://doi.org/10.1007/s10584-0172044-7.

Wiens, J. J. (2016). Climate-Related Local Extinctions Are Already Widespread among Plant and Animal Species. PLOS Biology, 14(12), e2001104. https://doi.org/10.1371/journal.pbio.2001104.

Wilson, J. R., Foxcroft, L. C., Geerts, S., Hoffman, M. T., MacFadyen, S., Measey, J., \&... van Wilgen, B. W. (2020). The Role of Environmental Factors in Promoting and Limiting Biological Invasions in South Africa. In B. W. van Wilgen, J. Measey, D. M. Richardson, J. R. Wilson, ve T. A. Zengeya (Ed.), Biological Invasions in South Africa (ss. 355-385). Cham: Springer International Publishing. https://doi.org/10.1007/978-3-030-323943_13.

Wu, C., Chen, D., Shen, J., Sun, X., \& Zhang, S. (2021). Estimating the distribution and productivity characters of Larix kaempferi in response to climate change. Journal of Environmental Management, 280, 111633. https://doi.org/10.1016/j.jenvman.2020.111633.

Yi, Y. J., Cheng, X., Yang, Z. F., \& Zhang, S. H. (2016). Maxent modeling for predicting the potential distribution of endangered medicinal plant (H. riparia Lour) in Yunnan, China. Ecological Engineering, 92, 260-269. https://doi.org/10.1016/j.ecoleng.2016.04.010.

Zhang, K., Yao, L., Meng, J., \& Tao, J. (2018). Maxent modeling for predicting the potential geographical distribution of two peony species under climate change. Science of The Total Environment, 634, 1326-1334. https://doi.org/10.1016/j.scitotenv.2018.04.112.

Zhao, H., Zhang, H., \& Xu, C. (2020). Study on Taiwania cryptomerioides under climate change: MaxEnt modeling for predicting the potential geographical distribution. Global Ecology and Conservation, 24, e01313. https://doi.org/10.1016/j.gecco.2020.e01313. 